\title{
Fluorescent contrast agents for tumor surgery (Review)
}

\author{
QI XIAO ${ }^{*}$, TIANMING CHEN ${ }^{2 *}$ and SHILIN CHEN ${ }^{3}$ \\ ${ }^{1}$ School of Life Science, Nanjing Normal University, Nanjing, Jiangsu 210046; \\ ${ }^{2}$ Department of Surgery, Nanjing Medical University Third Affiliated Hospital, Nanjing, Jiangsu 211166; \\ ${ }^{3}$ Department of Thoracic Surgery, Jiangsu Cancer Hospital, Jiangsu Institute of Cancer Research, \\ Nanjing Medical University Affiliated Cancer Hospital, Nanjing, Jiangsu 210009, P.R. China
}

Received July 4, 2017; Accepted April 13, 2018

DOI: $10.3892 /$ etm.2018.6401

\begin{abstract}
Cancer is a leading cause of cases of mortality worldwide. The most effective method to cure solid tumors is surgery. Every year, $>50 \%$ of cancer patients receive surgery to remove solid tumors. Surgery may increase the cure rate of most solid tumors by 4-11 fold. Surgery has many challenges, including identifying small lesions, locating metastases and confirming complete tumor removal. Fluorescence guidance describes a new approach to improve surgical accuracy. Near-infrared fluorescence imaging allows for real-time early diagnosis and intraoperative imaging of lesion tissue. The results of previous preclinical studies in the field of near-infrared fluorescence imaging are promising. This review provides examples introducing the three kinds of fluorescent dyes: The passive fluorescent dye indocyanine green, which has been approved by the Food and Drug Administration for clinical use in the USA, the fluorescent prodrug 5-aminolevulinic acid, a porphyrin precursor in the heme synthesis, and biomarker-targeted fluorescent dyes, which allow conjugation to different target sites.
\end{abstract}

\section{Contents}

1. Introduction

2. Passive fluorescent dye indocyanine green

3. 'Pro-dye' fluorescent agent 5-ALA

4. Biomarker-targeted fluorescent dyes

5. Conclusions

Correspondence to: Dr Shilin Chen, Department of Thoracic Surgery, Jiangsu Cancer Hospital, Jiangsu Institute of Cancer Research, Nanjing Medical University Affiliated Cancer Hospital, 42 Baiziting, Xuanwu, Nanjing, Jiangsu 210009, P.R. China E-mail: chens1201706@163.com

*Contributed equally

Key words: fluorescence guidance surgery, near infrared, fluorescent dyes

\section{Introduction}

Cancer is a leading cause of cases of mortality worldwide (1). Surgery is an effective method used to remove solid tumors, with $>50 \%$ of cancer patients undergoing surgery each year (2). As a matter of fact, surgical removal of the tumor may increase the cure rate of most solid tumor types by 4-11 fold (3).

Failure to obtain complete disease clearance due to incomplete resection, including positive tumor margins or metastatic cancer cells in lymph nodes, is a major challenge in tumor surgery and occurs in $20-60 \%$ of operations (2). Tumor cells may spread to distant host tissues, leading to metastatic disease, a well-known cause of mortality in patients with cancer (4). Following treatment, high levels of metastasis and the recurrence of cancer may be observed due to incomplete removal of the edges of the primary tumor (4). Surgery holds different challenges, including identifying small lesions, locating metastases, as well as confirming complete tumor removal (5-9).

To improve surgical accuracy, fluorescence guidance is an advisable approach. Near-infrared fluorescence (NIRF) imaging displays promising results in preclinical studies, allowing for real-time early diagnosis and intraoperative imaging lesion tissue (10-12). It describes the non-invasive use of near-infrared light to excite the contrast agent, after which the intensity of contrast agent fluorescence can be detected. Thus, the fluorescence represents the transformation of the molecular structure of the contrast agent, which is tissues in different diseases (4). NIRF guidance was introduced to improve the identification of lesions and guide the removal of these lesions (13). Compared with the more traditional approach of molecular imaging, which involves a radioactive tracer at $\mathrm{cm}$ resolution, NIRF provides higher resolution, allowing the identification of numerous details on the surface of the tissue (14). The fluorescence guidance technology is limited by the strong attenuation of the signal, meaning the technology would lose be less accurate with increasing depth (15). Intraoperative fluorescent molecular imaging agents have emerged as an innovative approach to guide surgical resection. There are three types of fluorescent molecular imaging agents, which include passive fluorescent dyes, 'pro-dye' fluorescent agents and biomarker-targeted fluorescent dyes. The current review introduces these types kinds of fluorescent contrast agents by using examples of each. 


\section{Passive fluorescent dye indocyanine green (ICG)}

ICG (Fig. 1) is a near-infrared (NIR) contrast dye, which has been approved by the Food and Drug Administration (FDA) for clinical use in the USA (3). ICG is a tricarbocyanine dye and a water-soluble organic compound synthesized in the Kodak Research laboratories in 1955 , it has been used to aid in medical diagnoses and to evaluate blood flow (16-18). ICG is able to easily penetrate tissues and cells, with an adverse reaction rate of $<0.1 \%$. In the past, several studies have demonstrated that ICG may be accumulating in metastatic tumors in the liver (19-23). As ICG is associated with biliary excretion, accumulation of ICG in cancerous tissue has been demonstrated to provide excellent contrast of intrahepatic nodules during surgery (24).

The mechanism of ICG accumulation in a tumor remains elusive. Previous studies have demonstrated that ICG undergoes hepatobiliary excretion (25-28). The excretion of ICG into the liver then bile may impact its clearance in different types of tumors. For hepatic tumors, it is assumed that organic-anion transporting polypeptides expressed on liver cells, transporter proteins and intracellular transporter proteins give rise to the tumor contrast $(24,29)$. For non-liver tumors, the enhanced permeability and retention (EPR) effect is the primary mechanism for the accumulation of ICG in solid carcinomas (30-33). The EPR mechanism has been associated with tumor environments, such as blood pressure, $\mathrm{pH}$, vascular endothelial cell separation, differences in local prostaglandins and bradykinin levels and the lack of angiogenesis in lymphatic vessels $(24,34)$.

Described by Matsumura and Maeda (35) for the first time in 1986, the EPR effect described defects in endothelial cells lead to the systematic and passive accumulation of small molecules, such as ICG, into the walls of tumor blood vessels. Once in the tumor microenvironment, the dye molecules are retained due to global properties, including shape, size, charge and polarity, rather than the tumor-specific ligand-receptor interaction mechanism (36).

The molecular structure of ICG comprises hydrophilic and hydrophobic moieties (37). Driven by its inherent chemical structure, ICG interacts with lipoprotein (LP) and phospholipids (38). ICG combines with LP in human blood circulation (39-41). LP interacts with the hydrophilic end of ICG and forms a complex (ICG-LP) with improved affinity for hydrophobic groups. During necrosis, the hydrophobic tails of phospholipids are exposed and changes in the affinity of ICG-LP to the ruptured lipid layer are observed (Fig. 2) (37). In addition, certain diseases, including malignant tumors, inflammation or trauma, may increase vascular permeability, allowing ICG-LP complexes to penetrate the walls of healthy blood vessels $(39,42)$.

Onda et al (43) revealed that 30 min after administration, ICG was internalized into tumor cells, where it remained for at least $24 \mathrm{~h}$. In normal tissue rapid clearance occurred. In the vicinity of 2-( $N$-(7-nitrobenz-2-oxa-1,3-diazol-4-yl) amino)-2-deoxyglucose, ICG exhibited rapid non-tissue specific extravasation, perhaps due to reversible non-covalent interactions with serum proteins, like albumin, displaying EPR effects contributing to ICG accumulation within the tumor tissue (30-33).

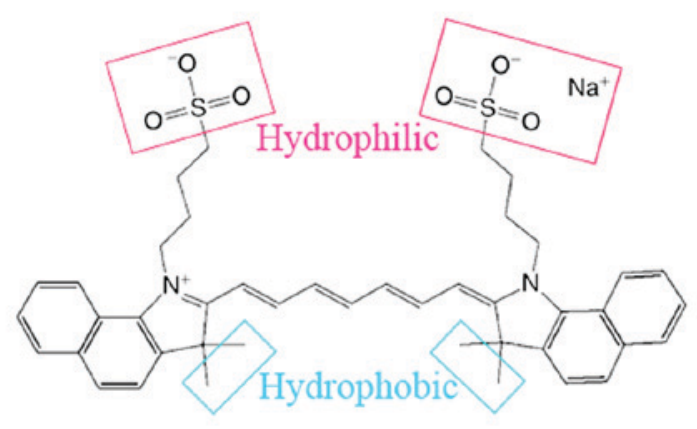

Figure 1. Structure of indocyanine green.

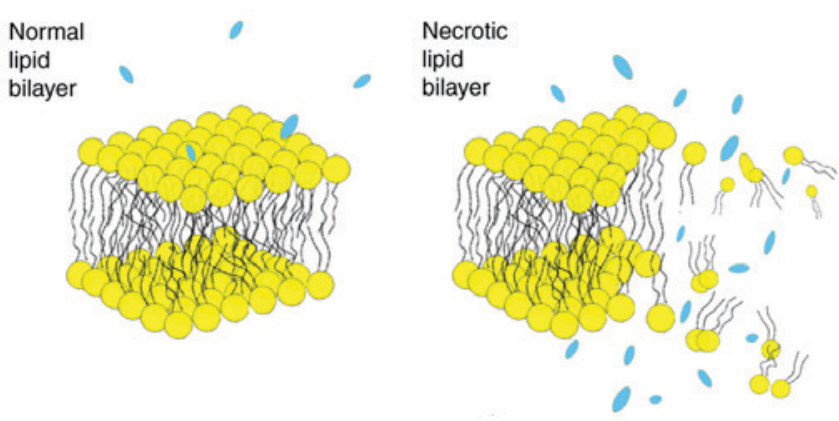

Figure 2. Normal lipid bilayer vs. necrotic lipid bilayer. Necrosis exposes the hydrophobic tails of the phospholipids. Indocyanine green-lipoprotein exhibits a distinct affinity for the phospholipids from the ruptured lipid bilayer.

It was further indicated that the intracellular accumulation of ICG may increase as the temperature increases; also, the authors suggested that ICG may be absorbed into the cells by binding to the cell membrane (43). Two molecules may influence the process of ICG uptake: Phospholipids and Pitstop2. The ability of ICG to interact with phospholipids allows it to bind to the cell membrane, the cells then uptake ICG; Pitstop2, the grid protein-dependent endocytosis inhibitor, is activated through the binding of extracellular molecules to the cell membrane and inhibits the uptake of ICG (44). Furthermore, the authors recommended that ICG may be absorbed into the cells by binding to the cell membrane (43).

The conflicting results of the fluorescence imaging often depend on tumor type, staging and microenvironment. The fluorescence emitted by ICG only penetrates $5-10 \mathrm{~mm}$ into the tissue, so the depth of the tumor influences the imaging result (45). Hill et al (46) stated that human leukocyte antigen (HLA) is a natural, biodegradable substance; ICG (0.0026-0.0052 mmol, $2.0-4.0 \mathrm{mg}$ ) loaded into HLA may become a nanoparticle. Hill et al (46) also indicated that tumor contrast with ICG nanoparticles was significantly improved compared with the use of regular ICG. This indicates that the size of ICG may influence the fluorescence image results.

A PubMed analysis of papers published over the last five years using ICG in surgery by tissue or cell type is given in Fig. 3. Liver cancer exhibits the highest publication numbers describing the use of ICG in surgery, followed by breast and cervical cancer. Publications describing the use of ICG in surgery have increased between 2011 and 2016, as Fig. 4 indicates. 


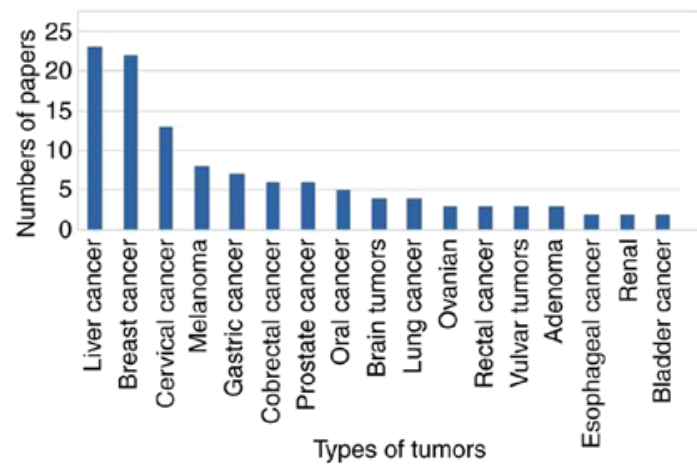

Figure 3. Number of papers published between 2011 and 2016, according to PubMed, describing the use of indocyanine green for surgery guidance for different types of tumor.

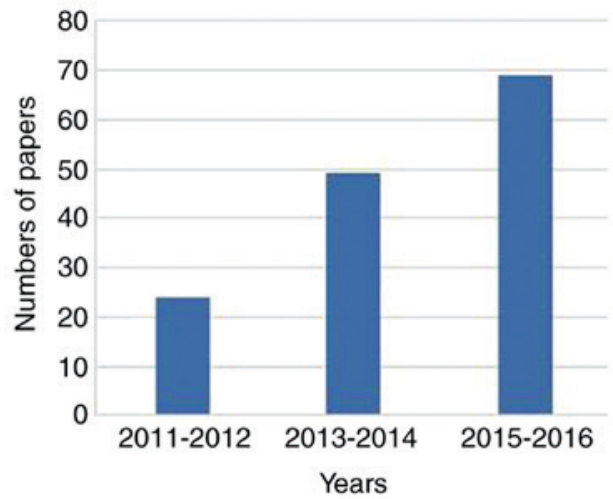

Figure 4. Number of papers published between 2011 and 2016, according to PubMed, describing the use of indocyanine green for surgery guidance over time.

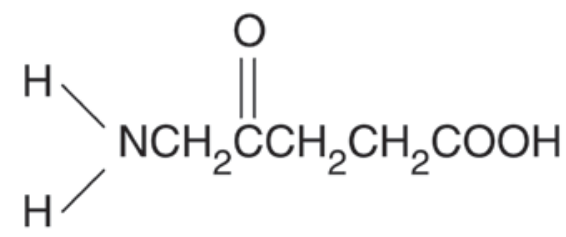

Figure 5. Structure of 5-aminolevulinic acid.

\section{3. 'Pro-dye' fluorescent agent 5-ALA}

5-aminolevulinic acid (5-ALA; Fig. 5) is a non-protein amino acid, which is a precursor in the porphyrin biosynthesis $(47,48)$. The ability of 5-ALA to act as a fluorescent agent originates from the accumulation of the light-sensitive protoporphyrin-IX (PpIX), which exhibits a distinct fluorescence spectrum when exposed to a certain wavelength (49). Through the insertion of a ferrous iron $\left(\mathrm{Fe}^{2+}\right)$, PpIX (Fig. 6) forms heme B, the prosthetic group of hemoglobin, myoglobin, cytochromes, catalases and peroxidases (47). PpIX is photosensitive, absorbing blue light (375-440 nm) and emitting red to pink fluorescence $(\sim 635 \mathrm{~nm})(48-50)$. Exogenous 5-ALA is the most commonly used molecule as a photosensitizing agent in intra-operative photodynamic detection of tumor tissue (51), and may become a 'pro-dye' fluorescence agent in fluorescence-guided surgery (FGS) (52-54).

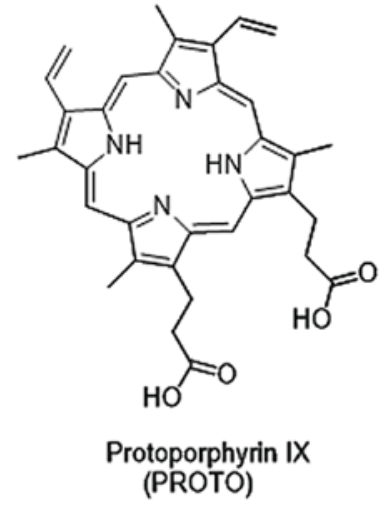

Figure 6. Structure of protoporphyrin-IX.

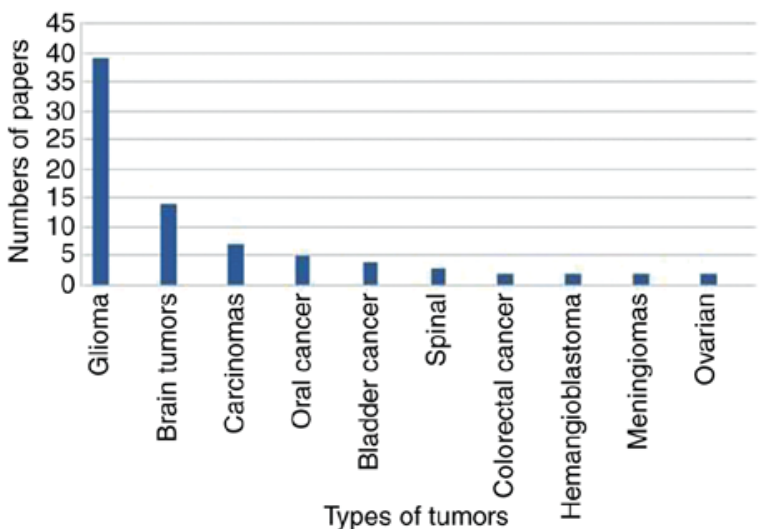

Figure 7. Number of papers published between 2011 and 2016, according to PubMed, describing the use of 5 -aminolevulinic acid for surgery guidance for different types of tumor.

Improved PpIX fluorescence following 5-ALA treatment is observed in different types of tumor cells and tissues (Fig. 7), validated through a comparison with a control group (55). Extensive research has demonstrated that increased PpIX fluorescence in tumor cells may be the result of influencing various tumor-associated properties, including heme biosynthesis, mitochondrial function and changes in porphyrin transporters (56).

The activity and expression profile of enzymes participating in heme biosynthesis differ between tumor and healthy cells or tissues. Eight enzymes were included in the heme biosynthesis pathway (57). Comparing the expression level of genes or activity of enzymes involved in heme biosynthesis between tumor, normal cells and tissues from studies indicated that the following enzymes exhibited significant differences in activity (21,58-72). The first enzyme in the heme biosynthesis is called ALA synthase, which catalyzes the formation of 5-ALA from glycine and succinyl-coenzyme A (CoA). Following the migration of 5-ALA from the mitochondrial matrix to the cytoplasm, ALA dehydratase, also referred to as porphobilinogen synthase, catalyzes the formation of porphobilinogen (PBG), by combining two molecules of 5-ALA. The connection of four PBG molecules yielding in hydroxymethyl bilane is catalyzed by the porphobilinogen deaminase (also known as hydroxylmethylbilane synthase). Uroporphyrinogen III decarboxylase (UROD) is involved in the fifth enzymatic step 
Table I. Changes in enzymatic activity and gene expression of enzymes participating in the heme biosynthesis pathway in various tumor tissues.

\begin{tabular}{|c|c|c|}
\hline Enzyme & Cancer type & Effects \\
\hline ALAS & $\begin{array}{l}\text { Colorectal cancer (58) } \\
\text { HCC } 4017 \text { non-small-cell lung cancer (59) } \\
\text { Lung cancer xenograft tumor (59) }\end{array}$ & $\begin{array}{l}\text { Gene expression significantly lower } \\
\text { Gene expression and protein level increased } \\
\text { Protein level increased }\end{array}$ \\
\hline PBGD & $\begin{array}{l}\text { Cervical cancer }(60) \\
\text { Prostate cancer }(61) \\
\text { Breast cancer }(62) \\
\text { Meningioma }(21) \\
\text { Bladder cancer }(63) \\
\text { Colon cancer }(64) \\
\text { Barrett's esophagus }(65,66) \\
\text { Esophageal cancer }(55,65)\end{array}$ & Gene expression and enzymatic activity increased \\
\hline UROD & $\begin{array}{l}\text { Friend virus-induced erythroleukemia } \\
\text { (mice) (67) } \\
\text { Breast tumor }(62) \\
\text { Head and neck cancer }(68)\end{array}$ & $\begin{array}{l}\text { Gene expression or enzyme activity increased in } \\
\text { initiation an progress } \\
\text { Enzyme activity increased } \\
\text { Gene expression increased }\end{array}$ \\
\hline FECH & $\begin{array}{l}\text { Liver cancer }(69) \\
\text { Bladder cancer }(63) \\
\text { Colorectal cancer }(58,64) \\
\text { Esophageal cancer }(58) \\
\text { Gastric cancer }(58) \\
\text { Rectal cancer }(58) \\
\text { Colon cancer }(58) \\
\text { Urothelial cancer }(70) \\
\text { Glioma cancer }(71) \\
\text { Breast cancer }(72)\end{array}$ & $\begin{array}{l}\text { Enzyme activity decreased } \\
\text { Enzyme activity decreased } \\
\text { Gene expression decreased } \\
\text { Gene expression decreased } \\
\text { Gene expression decreased } \\
\text { Gene expression decreased } \\
\text { Gene expression decreased }\end{array}$ \\
\hline
\end{tabular}

ALAS, 5-aminolevulinic acid synthase; PBGD, porphobilinogen deaminase; UROD, uroporphyrinogen III decarboxylase; FECH, ferrochelatase.

of the heme biosynthesis pathway, where uroporphyrinogen III is decarboxylated by UROD giving proporphyrinogen III. Ferrochelatase $(\mathrm{FECH})$ catalyzes the conversion of PpIX to heme $\mathrm{b}$, making it the last enzyme utilized in the heme biosynthesis.

In order to make it clear that these enzymes are differentially expressed in the tumors, Table I $(21,58-72)$ illustrates the changes observed in gene expression and enzyme activity linked to the heme biosynthesis pathway of various tumor tissues compared to normal tissue. The data provided may further be used a guide aiding the decision as to which tumor types may exhibit improved surgical results through the use of 5-ALA-mediated PpIX florescence.

Succinyl-CoA, one of the two starting materials of the $\mathrm{PpIX} /$ heme biosynthesis, is a metabolite produced in the tricarboxylic acid (TCA) cycle. In order to prevent the accumulation of metabolites from the TCA cycle, as well as mitochondrial NADH, a connection between the glucose metabolism, TCA cycle and the heme biosynthesis has been established (73). That is to say, Succinyl-CoA, a metabolite produced in the TCA cycle, participated in the first step of PpIX/heme biosynthesis.
In cancer cells, metabolic reprogramming from the TCA cycle into aerobic glycolysis, generating glutamine for energy, may lead to the accumulation of TCA cycle metabolites and the activation of the heme biosynthesis to remove those metabolites (74). Activation of heme biosynthesis may lead to PpIX accumulation due to FECH saturation (56). Effective 5-ALA absorption and the transport of different porphyrin metabolites may further affect the PpIX accumulation in cells. In theory, the improved 5-ALA-PpIX in tumor cells may be triggered by certain processes, including elevated ALA uptake, improved porphyrin activity and reduced PpIX activity. An increase in 5-ALA uptake has been identified through elevated levels of PpIX in tumor cells (75). Furthermore, studies have indicated that high and low PpIX 5-ALA absorption were not significantly different between cell lines $(64,76,77)$. Nakanishi et al (78) demonstrated that there was no correlation between 5-ALA-induced PpIX accumulation and the uptake clearance of 5-ALA. The aforementioned study also revealed that ALA uptake rates were far greater than maximum conversion rates of ALA to PpIX in LS-180,T24,A2780, DU145 and MCF-7 cell lines. ALA uptake is not the only decisive factor to enhance ALA-PpIX fluorescence in tumor cells. A 
Table II. Comparison of three different fluorescence-based dyes.

\begin{tabular}{lcl}
\hline Dye & Targeted & \multicolumn{1}{c}{ Administration } \\
\hline ICG & No & Injection \\
5-ALA & No & Injection or oral \\
Biomarker & Yes & Depends on the dye \\
\hline
\end{tabular}

ICG, indocyanine green; 5-ALA, 5-aminolevulinic acid.

porphyrin transporter that is postulated to be linked to the porphyrin synthesis is the adenosine 5'-triphosphate-binding cassette subgroup B member 6 (ABCB6), which was originally described as a transporter protein on the outer mitochondrial outer membrane (79). ABCB6 interacts with various porphyrins, including coproporphyrinogen III, PpIX and hemoglobin, with the highest affinity recorded for coproporphyrinogen III (46). Therefore, ABCB6 was thought to be primarily involved in the transporting coproporphyrin III into the mitochondria for $\mathrm{PpIX/heme} \mathrm{b} \mathrm{synthesis} \mathrm{(79).} \mathrm{Increased} \mathrm{ABCB6} \mathrm{expression} \mathrm{has}$ been linked to an increase in fluorescence in human glioma tissues allowing for better contrast in fluorescence-guided surgery, via more sufficient PpIX accumulation (80). ABCB6 is located in the cell membrane and Golgi apparatus, and transports coproporphyrinogen III between the cellular departments (81-83). An enhanced ABCB6 function may be observed at increased coproporphyrinogen III concentration, reducing the intracellular concentration of PpIX/hemoglobin (46). The net influence of ABCB6 on 5-ALA-PpIX levels in the cells may depend on the relative ABCB6 activity in the mitochondria and cell membranes (56).

In the plasma membrane, ATP-binding cassette sub-family G member 2 (ABCG2), a transporter, serves the most important role in transporting PpIX. Studies have demonstrated that increased ABCG2 activity reduces the intracellular PpIX level following 5-ALA stimulation, and the cell lines with high ABCG2 expression or activity often exhibit decreased 5-ALA-PpIX fluorescence $(84,85)$. Robey et al $(84)$ indicated that the use of ABCG2 transport inhibitors would enhance 5-ALA-PpIX fluorescence.

\section{Biomarker-targeted fluorescent dyes}

Several NIR fluorescent dyes have been developed and incorporated, for example with antibodies $(86,87)$, nanoparticles (88) or encapsulated within nanomaterials $(89,90)$, to be used as contrast agents for molecular imaging of different tumors (4). Researchers have identified that elevated levels of fibroblast activation protein (FAP) in stromal fibroblasts are associated with aggressive cancer types (91-95). FAP is a type II salivary glycoprotein with the ability to cleave biological peptides, including collagen and proteolytic enzymes, and serve a central role in the aggressiveness of the solid tumors. FAP is expressed in stromal fibroblasts of several types of cancer, but not in healthy tissue; it is used as a tumor marker that has drawn increasing attention $(91,96)$. Rüger et al (90) linked anti-single-chain variable fragment directed against FAP antibody fragments to quenched liposomes, which became a novel fluorescence diagnostic contrast dye termed anti-FAP-IL. Anti-FAP-IL antibodies were used to ensure the specificity and fluorescence imaging of FAP expression cells and tumor muscle fibroblasts in mice xenotransplantation (96).

Carbohydrate antigen 19.9 (CA19.9) is a ligand of epithelial leukocyte adhesion molecules and its overexpression has been found in some malignancies as well as in some non-malignant conditions (97-101). CA19.9 is an attractive target for pancreatic ductal adenocarcinoma (PDAC) imaging, due to its high expression on tumors, compared with healthy pancreatic tissue $(102,103)$. The usage of CA19.9 as biomarkers for PDAC led to the identification of several antibodies, including the characterization of the fully human monoclonal antibody 5B1, which binds to extracellular epitopes of CA19.9 with low nanomolar affinity (104-106). So Houghton et al (107) generated three modular tools, including ${ }^{89} \mathrm{Zr}-{ }^{\mathrm{ss}} \mathrm{DFO}-5 \mathrm{~B} 1,{ }^{\mathrm{ss}} \mathrm{FL}-5 \mathrm{~B} 1$ and ${ }^{89} \mathrm{Zr}^{-}{ }^{\text {ss }}$ dual-5B1. These modular tools can target CA19.9, which is an important molecule in invasion and metastasis of many cancers, including PDAC (103). The results revealed that the three modular tools evaluated displayed excellent uptake in the CA19.9 positive xenograph model of PDAC, indicating that each of them is likely to improve the detection rates of tumor of patients with PDAC (107).

The fluorescent gold nanoparticles synthesized by Li et al (108) bind to diatrizoic acid and the nucleolin-targeted AS1411 aptamer. This is a type of fluorescence-guided aptamer-targeted probe. Apart from providing visible fluorescence for detecting, the probe also exhibited high water-solubility, good biocompatibility and strong X-ray attenuation used in computed tomography (CT) contrast enhancement. The probes were intravenously injected into CL1-5 tumor-bearing mice and detection experiments, which included CT imaging and fluorescence detection 30 min post injection, were performed. The results demonstrated that fluorescence nanoparticle conjugates, used as molecular imaging agents to indicate the tumor location by CT imaging, may be easily observed on CT images with the naked eye (108).

Cysteine protease is another biomarker that is highly upregulated in the tumor cells and the surrounding matrix of tumor support cells in multiple types of cancers (109). Fluorescent contrast agents that may be helpful for dynamic monitoring in vivo and used as imaging contrast agents for FGS may improve the detection rates for tumors (110). Researchers designed and synthesized a series of NIR fluorescent probes, using the latent lysosomotropic effect to promote the cell retention of protease activation. These probes exhibit tumor-specific retention, rapid activation kinetics and rapid system distribution. Furthermore, they may be used to detect multiple types of cancer, including breast, colon and lung cancer (110).

The most common biomarker used for targeted fluorescence is folate, a B vitamin involved in metabolic processes, including DNA and RNA synthesis, epigenetic processes, cell proliferation and lung adenocarcinoma survival (111). The folate receptor (FR) family consists of four members, with only FR- $\alpha$ and FR- $\beta$ displaying high affinities for folic acid. When expressed in the cavity surface of polarized epithelial 
cells, FR- $\alpha$ is able to prevent binding of the serum folate salt (111-114). The FR- $\alpha$ expression in lung adenocarcinoma (1-3,000,000 receptor/cancer cells) appears more connected with serum folic acid than in normal pulmonary epithelial cells (115-118). For the purpose of diagnosis, FR- $\alpha$ provides a reasonable molecular target for lung adenocarcinoma. Two contrast agents, EC17 and OTL38, have been proposed to image ovarian and lung adenocarcinomas during surgery $(12,119)$. These agents are similar in that they target FR- $\alpha$ via a folate ligand. Although EC17 and OTL38 use the same ligand, they have two different fluorochromes: EC17 contains a fluorescein dye and OTL38 contains a cyanine dye (118). Fluorescein is in the visible wavelength and the cyanine is in the NIR range. De Jesus et al (118) revealed that OTL38 appears to have superior sensitivity and brightness compared to EC17 in a preclinical testing. This conclusion is consistent with the accepted belief that NIR dyes exhibit less auto fluorescence and scattering compared with visible wavelength fluorochromes (118).

\section{Conclusions}

Fluorescent contrast agents may guide surgeons in making real-time decisions during surgery. ICG is an NIR contrast dye, which was approved by the FDA for clinical use in the USA. It is a water-soluble organic compound, which may easily penetrate tissues and cells with an adverse reaction rate of $<0.1 \%$. The EPR influence is the major mechanism by which ICG accumulates in solid cancer. ICG is processed by the excretory pathways of the biliary system and may offer superiority in some tumor nodules during surgery. 5-ALA is a natural amino acid and a natural prodrug that metabolizes to the heme precursor PpIX. 5-ALA, through oral administration, increases the PpIX accumulation in the tumor tissue and subsequent photosensitizing may guide tumor resection. Fluorescent dyes have been developed and combined with antibodies or nanoparticles to function as contrast agents for molecular imaging by increasing the binding to the target site and providing more accurate information during tumor resection. Increasing studies focus on combining these different advantages into one dye, which it is believed will further the development of fluorescent contrast agents. Table II provides a brief summary of targeting abilities and methods of administration of the three types fluorescent contrast agents discussed in the current review. Combining these imaging agents for clinical use may provide more options in tumor surgeries. The application of contrast agents may significantly improve the surgery outcome.

\section{Acknowledgements}

Not applicable.

\section{Funding}

The present study was supported by the Key Development Plan for Social Development of Jiangsu Province (grant no. SBE2016750057), and Jiangsu Provincial Key R \& D Program Social Development Clinical Frontier Technology Project (Application of Image-guided Precise Tumor Surgical Equipment in Esophageal Cancer Surgery) (grant no. BE2016731).

\section{Availability of data and materials}

The analyzed data sets generated during the present study are available from the corresponding author on reasonable request.

\section{Authors' contributions}

QX contributed to the conception and design of the study, analysis of data, and drafting and revising of the manuscript. TC was involved in analyzing the data, as well as drafting the manuscript and revising it critically for important intellectual content. SC contributed to the conception of the study, provided financial support for the paper, gave approval of the version to be published, and supervised and directed the research group. All authors agreed to be accountable for all aspects of the work in ensuring that questions related to the accuracy or integrity of any part of the work are appropriately investigated and resolved.

\section{Ethics approval and consent to participate}

Not applicable.

\section{Patient consent for publication}

Not applicable.

\section{Competing interests}

The authors declare that they have no competing interests.

\section{References}

1. Jemal A, Bray F, Center MM, Ferlay J, Ward E and Forman D: Global cancer statistics. CA Cancer J Clin 61: 69-90, 2011.

2. Aliperti LA, Predina JD, Vachani A and Singhal S: Local and systemic recurrence is the Achilles heel of cancer surgery. Ann Surg Oncol 18: 603-607, 2011.

3. Jiang JX, Keating JJ, Jesus EM, Judy RP, Madajewski B, Venegas O, Okusanya OT and Singhal S: Optimization of the enhanced permeability and retention effect for near-infrared imaging of solid tumors with indocyanine green. Am J Nucl Med Mol Imaging 5: 390-400, 2015.

4. Tansi FL, Rüger R, Böhm C, Kontermann RE, Teichgraeber UK, Fahr A and Hilger I: Potential of activatable FAP-targeting immunoliposomes in intraoperative imaging of spontaneous metastases. Biomaterials 88: 70-82, 2016.

5. Fedor D, Johnson WR and Singhal S: Local recurrence following lung cancer surgery: Incidence, risk factors, and outcomes. Surg Oncol 22: 156-161, 2013.

6. Zaman M, Bilal H, Woo CY and Tang A: In patients undergoing video-assisted thoracoscopic surgery excision, what is the best way to locate a subcentimetre solitary pulmonary nodule in order to achieve successful excision? Interact Cardiovasc Thorac Surg 15: 266-272, 2012.

7. Chella A, Lucchi M, Ambrogi MC, Menconi G, Melfi FM, Gonfiotti A, Boni G and Angeletti CA: A pilot study of the role of TC-99 radionuclide in localization of pulmonary nodular lesions for thoracoscopic resection. Eur J Cardiothoracic Surg 18: 17-21, 2000.

8. Powell TI, Jangra D, Clifton JC, Lara-Guerra H, Church N, English J, Evans K, Yee J, Coxson H, Mayo JR and Finley RJ: Peripheral lung nodules: Fluoroscopically guided video-assisted thoracoscopic resection after computed tomography-guided localization using platinum microcoils. Ann Surg 240: 481-489, 2004.

9. Eichfeld U, Dietrich A, Ott R and Kloeppel R: Video-assisted thoracoscopic surgery for pulmonary nodules after computed tomography-guided marking with a spiral wire. Ann Thorac Surg 79: 313-317, 2005. 
10. Licha K, Riefke B, Ebert B and Grötzinger C: Cyanine dyes as contrast agents in biomedical optical imaging. Acad Radiol 9 (Suppl 2): S320-S322, 2002.

11. Luker GD and Luker KE: Optical imaging: Current applications and future directions. J Nucl Med 49: 1-4, 2008.

12. van Dam GM, Themelis G, Crane LM, Harlaar NJ, Pleijhuis RG, Kelder W, Sarantopoulos A, de Jong JS, Arts HJ, van der Zee AG, et al: Intraoperative tumor-specific fluorescence imaging in ovarian cancer by folate receptor- $\alpha$ targeting: First in-human results. Nat Med 17: 1315-1319, 2011.

13. Polom K, Murawa D, Rho YS, Nowaczyk P, Hünerbein M and Murawa P: Current trends and emerging future of indocyanine green usage in surgery and oncology: A literature review. Cancer 117: 4812-4822, 2011.

14. van Leeuwen FW, Hardwick JC and van Erkel AR: Luminescence-based imaging approaches in the field of interventional molecular imaging. Radiol 276: 12-29, 2015.

15. KleinJan GH, Bunschoten A, van den Berg NS, Olmos RA Klop WM, Horenblas S, van der Poel HG, Wester HJ and van Leeuwen FW: Fluorescence guided surgery and tracer-dose, fact or fiction? Eur J Nucl Med Mol Imaging 43: 1857-1867, 2016.

16. Brülisauer M, Moneta G, Jager $\mathrm{K}$ and Bollinger A: Infrared fluorescence videomicroscopy with indocyanine green (Cardiogreen). Adv Exp Med Biol 220: 219-221, 1987.

17. Chen CY, Fancher RM, Ruan Q, Marathe P, Rodrigues AD and Yang Z: A liquid chromatography tandem mass spectrometry method for the quantification of indocyanine green in dog plasma and bile. J Pharm Biomed Anal 47: 351-359, 2008.

18. Engel E, Schraml R, Maisch T, Kobuch K, König B, Szeimies RM, Hillenkamp J, Bäumler W and Vasold R: Light-induced decomposition of indocyanine green. Invest Ophthalmol Vis Sci 49: 1777-1783, 2008.

19. van der Vorst JR, Schaafsma BE, Hutteman M, Verbeek FP, Liefers GJ, Hartgrink HH, Smit VT, Löwik CW, van de Velde CJ, Frangioni JV and Vahrmeijer AL: Near-infrared fluorescence-guided resection of colorectal liver metastases. Cancer 119: 3411-3418, 2013.

20. Yokoyama N, Otani T, Hashidate H, Maeda C, Katada T, Sudo N, Manabe S, Ikeno Y, Toyoda A and Katayanagi N: Real-time detection of hepatic micrometastases from pancreatic cancer by intraoperative fluorescence imaging: Preliminary results of a prospective study. Cancer 118: 2813-2819, 2012.

21. Rajaraman P, Schwartz BS, Rothman N, Yeager M, Fine HA, Shapiro WR, Selker RG, Black PM and Inskip PD: Delta-aminolevulinic acid dehydratase polymorphism and risk of brain tumors in adults. Environ Health Perspect 113 1209-1211, 2005.

22. Iida G, Asano K, Seki M, Ishigaki K, Teshima K, Yoshida O, Edamura K and Kagawa Y: Intraoperative identification of canine hepatocellular carcinoma with indocyanine green fluorescent imaging. J Small Anim Pract 54: 594-600, 2013.

23. Gotoh K, Yamada T, Ishikawa O, Takahashi H, Eguchi H, Yano M, Ohigashi H, Tomita Y, Miyamoto Y and Imaoka S: A novel image-guided surgery of hepatocellular carcinoma by indocyanine green fluorescence imaging navigation. J Surg Oncol 100: 75-79, 2009.

24. Ishizawa T, Masuda K, Urano Y, Kawaguchi Y, Satou S, Kaneko J, Hasegawa K, Shibahara J, Fukayama M, Tsuji S, et al: Mechanistic background and clinical applications of indocyanine green fluorescence imaging of hepatocellular carcinoma. Ann Surg Oncol 21: 440-448, 2014.

25. Cherrick GR, Stein SW, Leevy CM and Davidson CS Indocyanine green: Observations on its physical properties, plasma decay, and hepatic extraction. J Clin Invest 39, 592-600, 1960.

26. Cornelius CE, Ben-Ezzer J and Arias IM: Binding of sulfobromophthalein sodium (BSP) and other organic anions by isolated hepatic cell plasma membranes in vitro. Proc Soc Exp Biol Med 124: 665-667, 1967.

27. Hunton DB, Bollman JL and Hoffman HN: Studies of hepatic function with indocyanine green. Gastroenterology 39: 713-724, 1960.

28. Leevy CM and Bender J: Physiology of dye extraction by the liver: Comparative studies of sulfobromophthalein and indocyanine green. Ann NY Acad Sci 111: 161-176, 1963.

29. Shibasaki Y, Sakaguchi T, Hiraide T, Morita Y, Suzuki A, Baba S, Setou M and Konno H: Expression of indocyanine green-related transporters in hepatocellular carcinoma. J Surg Res 193: 567-576, 2015.
30. Holt D, Okusanya O, Judy R, Venegas O, Jiang J, DeJesus E, Eruslanov E, Quatromoni J, Bhojnagarwala P, Deshpande $\mathrm{C}$, et al: Intraoperative near-infrared imaging can distinguish cancer from normal tissue but not inflammation. PLoS One 9: e103342, 2014.

31. Kosaka N, Mitsunaga M, Longmire MR, Choyke PL and Kobayashi H: Near infrared fluorescence-guided real-time endoscopic detection of peritoneal ovarian cancer nodules using intravenously injected indocyanine green. Int J Cancer 129: 1671-1677, 2011

32. Maeda H, Nakamura $H$ and Fang J: The EPR effect for macromolecular drug delivery to solid tumors: Improvement of tumor uptake, lowering of systemic toxicity, and distinct tumor imaging in vivo. Adv Drug Deliv Rev 65: 71-79, 2013.

33. Madajewski B, Judy BF, Mouchli A, Kapoor V, Holt D, Wang MD, Nie S and Singhal S: Intraoperative near-infrared imaging of surgical wounds after tumor resections can detect residual disease. Clin Cancer Res 18: 5741-5751, 2012.

34. Shin EH, Li Y, Kumar U, Sureka HV, Zhang X and Payne CK: Membrane potential mediates the cellular binding of nanoparticles. Nanoscale 5: 5879-5886, 2013.

35. Matsumura Y and Maeda H: A new concept for macromolecular therapeutics in cancer chemotherapy: Mechanism of tumoritropic accumulation of proteins and the antitumor agent smancs. Cancer Res 46: 6387-6392, 1986.

36. Heneweer C, Holland JP, Divilov V, Carlin S and Lewis JS Magnitude of enhanced permeability and retention effect in tumors with different phenotypes: $89 \mathrm{Zr}$-albumin as a model system. J Nucl Med 52: 625-633, 2011.

37. Fang C, Wang K, Zeng C, Chi C, Shang W, Ye J, Mao Y, Fan Y, Yang J, Xiang N, et al: Illuminating necrosis: From mechanistic exploration to preclinical application using fluorescence molecular imaging with indocyanine green. Sci Rep 6: 21013, 2016.

38. Hyun H, Park MH, Owens EA, Wada H, Henary M, Handgraaf HJ, Vahrmeijer AL, Frangioni JV and Choi HS: Structure-inherent targeting of near-infrared fluorophores for parathyroid and thyroid gland imaging. Nat Med 21: 192-197, 2015.

39. Yoneya S, Saito T, Komatsu Y, Koyama I, Takahashi K and Duvoll-Young J: Binding properties of indocyanine green in human blood. Invest Ophthalmol Vis Sci 39: 1286-1290, 1998.

40. Baker KJ: Binding of sulfobromophthalein (BSP) sodium and indocyanine green (ICG) by plasma alpha-1 lipoproteins. Proc Soc Exp Biol Med 122: 957-963, 1966.

41. Janecki J and Krawcynski J: Labeling with indocyanine green of serum protein from normal persons and patients with acute viral hepatitis. Clin Chem 16: 1008-1011, 1970

42. Desmettre T, Devoisselle JM and Mordon S: Fluorescence properties and metabolic features of indocyanine green (ICG) as related to angiography. Surv Ophthalmol 45: 15-27, 2000.

43. Onda N, Kimura M, Yoshida T and Shibutani M: Preferential tumor cellular uptake and retention of indocyanine green for in vivo tumor imaging. Int J Cancer 139: 673-682, 2016.

44. von Kleist L, Stahlschmidt W, Bulut H, Gromova K, Puchkov D, Robertson MJ, MacGregor KA, Tomilin N, Pechstein A, Chau N, et al: Role of the clathrin terminal domain in regulating coated pit dynamics revealed by small molecule inhibition. Cell 146: 471-484, 2011

45. Kaibori M, Matsui K, Ishizaki M, Iida H, Okumura T, Sakaguchi T, Inoue $\mathrm{K}$, Ikeura $\mathrm{T}$, Asano $\mathrm{H}$ and Kon $\mathrm{M}$ : Intraoperative detection of superficial liver tumors by fluorescence imaging using indocyanine green and 5-aminolevulinic acid. Anticancer Res 36: 1841-1849, 2016.

46. Hill TK, Abdulahad A, Kelkar SS, Marini FC, Long TE Provenzale JM and Mohs AM: Indocyanine green-loaded nanoparticles for image-guided tumor surgery. Bioconjug Chem 26: 294-303, 2015 .

47. Ishizuka M, Abe F, Sano Y, Takahashi K, Inoue K, Nakajima M, Kohda T, Komatsu N, Ogura S and Tanaka T: Novel development of 5-aminolevurinic acid (ALA) in cancer diagnoses and therapy. Int Immunopharmacol 11: 358-365, 2011.

48. Nakamura M, Nishikawa J, Hamabe K, Goto A, Nishimura J, Shibata H, Nagao M, Sasaki S, Hashimoto S, Okamoto T and Sakaida I: Preliminary study of photodynamic diagnosis using 5 -aminolevulinic acid in gastric and colorectal tumors. World $\mathrm{J}$ Gastroenterol 21: 6706-6712, 2015.

49. Leroy HA, Vermandel M, Lejeune JP, Mordon S and Reyns N: Fluorescence guided resection and glioblastoma in 2015: A review. Lasers Surg Med 47: 441-451, 2015. 
50. Kitada M, Ohsaki Y, Matsuda Y, Hayashi S and Ishibashi K Photodynamic diagnosis of pleural malignant lesions with a combination of 5-aminolevulinic acid and intrinsic fluorescence observation systems. BMC Cancer 15: 174, 2015.

51. Friesen SA, Hjortland GO, Madsen SJ, Hirschberg $\mathrm{H}$, Engebraten O, Nesland JM and Peng Q: 5-Aminolevulinic acid-based photodynamic detection and therapy of brain tumors (review). Int J Oncol 21: 577-582, 2002.

52. Colditz MJ and Jeffree RL: Aminolevulinic acid (ALA)-protoporphyrin IX fluorescence guided tumour resection. Part 1: Clinical, radiological and pathological studies. J Clin Neurosci 19: 1471-1474, 2012.

53. Colditz MJ, Leyen K and Jeffree RL: Aminolevulinic acid (ALA)-protoporphyrin IX fluorescence guided tumour resection. Part 2: Theoretical, biochemical and practical aspects. J Clin Neurosci 19: 1611-1616, 2012.

54. Eljamel S: 5-ALA fluorescence image guided resection of glioblastoma multiforme: A meta-analysis of the literature. Int J Mol Sci 16: 10443-10456, 2015.

55. Nokes B,Apel M,Jones C, Brown G and Lang JE: Aminolevulinic acid (ALA): Photodynamic detection and potential therapeutic applications. J Surg Res 181: 262-271, 2013.

56. Yang X, Palasuberniam P, Kraus D and Chen B: Aminolevulinic acid-based tumor detection and therapy: Molecular mechanisms and strategies for enhancement. Int J Mol Sci 16: 25865-25880, 2015.

57. Ponka P: Cell biology of heme. Am J Med Sci 318: 241-256, 1999.

58. Kemmner W, Wan K, Rüttinger S, Ebert B, Macdonald R, Klamm U and Moesta KT: Silencing of human ferrochelatase causes abundant protoporphyrin-IX accumulation in colon cancer. FASEB J 22: 500-509, 2008.

59. Hooda J, Cadinu D, Alam MM, Shah A, Cao TM, Sullivan LA, Brekken R and Zhang L: Enhanced heme function and mitochondrial respiration promote the progression of lung cancer cells. PloS One 8: e63402, 2013.

60. Gonçalves TL, Erthal F, Corte CL, Müller LG, Piovezan CM Nogueira CW and Rocha JB: Involvement of oxidative stress in the pre-malignant and malignant states of cervical cancer in women. Clin Biochem 38: 1071-1075, 2005.

61. Neslund-Dudas C, Levin AM, Rundle A, Beebe-Dimmer J, Bock CH, Nock NL, Jankowski M, Datta I, Krajenta R, Dou QP, et al: Case-only gene-environment interaction between ALAD tagSNPs and occupational lead exposure in prostate cancer. Prostate 74: 637-646, 2014

62. Navone NM, Polo CF, Frisardi AL, Andrade NE and Battle AM: Heme biosynthesis in human breast cancer-mimetic 'in vitro' studies and some heme enzymic activity levels. Int J Biochem 22: 1407-1411, 1990.

63. Krieg RC, Fickweiler S, Wolfbeis OS and Knuechel R: Cell-type specific protoporphyrin IX metabolism in human bladder cancer in vitro. Photochem Photobiol 72: 226-233, 2000.

64. Krieg RC, Messmann H, Rauch J, Seeger S and Knuechel R: Metabolic characterization of tumor cell-specific protoporphyrin IX accumulation after exposure to 5-aminolevulinic acid in human colonic cells. Photochem Photobiol 76: 518-525, 2002.

65. Hinnen P, de Rooij FW, van Velthuysen ML, Edixhoven A, van Hillegersberg R, Tilanus HW, Wilson JH and Siersema PD: Biochemical basis of 5-aminolaevulinic acid-induced protoporphyrin IX accumulation: A study in patients with (pre) malignant lesions of the oesophagus. Br J Cancer 78: 679-682, 1998.

66. Hinnen P, de Rooij FW, Terlouw EM, Edixhoven A van Dekken H, van Hillegersberg R, Tilanus HW, Wilson JH and Siersema PD: Porphyrin biosynthesis in human Barrett's oesophagus and adenocarcinoma after ingestion of 5-aminolaevulinic acid. Br J Cancer 83: 539-543, 2000.

67. Misawa Y, Tojo A and Shibuya M: Isolation of genes highly expressed in early and late stages of Friend virus-induced erythroleukemia in mice. Biochem Biophys Res Commun 170: 39-45, 1990

68. Ito E, Yue S, Moriyama EH, Hui AB, Kim I, Shi W, Alajez NM, Bhogal N, Li G, Datti A, et al: Uroporphyrinogen decarboxylase is a radiosensitizing target for head and neck cancer. Sci Transl Med 3: 67ra67, 2011.

69. Dailey HA and Smith A: Differential interaction of porphyrins used in photoradiation therapy with ferrochelatase. Biochem J 223: 441-445, 1984
70. Miyake M, Ishii M, Kawashima K, Kodama T, Sugano K, Fujimoto K and Hirao Y: siRNA-mediated knockdown of the heme synthesis and degradation pathways: Modulation of treatment effect of 5-aminolevulinic acid-based photodynamic therapy in urothelial cancer cell lines. Photochem Photobiol 85: 1020-1027, 2009.

71. Teng L, Nakada M, Zhao SG, Endo Y, Furuyama N, Nambu E, Pyko IV, Hayashi Y and Hamada JI: Silencing of ferrochelatase enhances 5-aminolevulinic acid-based fluorescence and photodynamic therapy efficacy. Br J Cancer 104: 798-807, 2011.

72. Yang $\mathrm{X}, \mathrm{Li}$ W, Palasuberniam $\mathrm{P}$, Myers KA, Wang $\mathrm{C}$ and Chen B: Effects of silencing heme biosynthesis enzymes on 5-aminolevulinic acid-mediated protoporphyrin IX fluorescence and photodynamic therapy. Photochem Photobiol 91: 923-930, 2015.

73. Frezza C, Zheng L, Folger O, Rajagopalan KN, MacKenzie ED, Jerby L, Micaroni M, Chaneton B, Adam J, Hedley A, et al: Haem oxygenase is synthetically lethal with the tumour suppressor fumarate hydratase. Nature 477: 225-228, 2011.

74. Ward PS and Thompson CB: Metabolic reprogramming: A cancer hallmark even warburg did not anticipate. Cancer Cell 21: 297-308, 2012

75. Ohgari Y, Nakayasu Y, Kitajima S, Sawamoto M, Mori H, Shimokawa O, Matsui $\mathrm{H}$ and Taketani S: Mechanisms involved in delta-aminolevulinic acid (ALA)-induced photosensitivity of tumor cells: Relation of ferrochelatase and uptake of ALA to the accumulation of protoporphyrin. Biochem Pharmacol 71: 42-49, 2005.

76. Gibson SL, Nguyen ML, Havens JJ, Barbarin A and Hilf R: Relationship of delta-aminolevulinic acid-induced protoporphyrin IX levels to mitochondrial content in neoplastic cells in vitro. Biochem Biophys Res Commun 265: 315-321, 1999.

77. Gibson SL, Havens JJ, Foster TH and Hilf R: Time-dependent intracellular accumulation of delta-aminolevulinic acid, induction of porphyrin synthesis and subsequent phototoxicity. Photochem Photobiol 65: 416-421, 1997.

78. Nakanishi T, Ogawa T, Yanagihara C and Tamai I: Kinetic evaluation of determinant factors for cellular accumulation of protoporphyrin IX induced by external 5-aminolevulinic acid for photodynamic cancer therapy. J Pharm Sci 104: 3092-3100, 2015.

79. Krishnamurthy PC, Du G, Fukuda Y, Sun D, Sampath J, Mercer KE, Wang J, Sosa-Pineda B, Murti KG and Schuetz JD: Identification of a mammalian mitochondrial porphyrin transporter. Nature 443: 586-589, 2006.

80. Zhao SG, Chen XF, Wang LG, Yang G, Han DY, Teng L, Yang MC, Wang DY, Shi C, Liu YH, et al: Increased expression of ABCB6 enhances protoporphyrin IX accumulation and photodynamic effect in human glioma. Ann Surg Oncol 20: 4379-4388, 2013.

81. Paterson JK, Shukla S, Black CM, Tachiwada T, Garfield S, Wincovitch S, Ernst DN, Agadir A, Li X, Ambudkar SV, et al: Human ABCB6 localizes to both the outer mitochondrial membrane and the plasma membrane. Biochemistry 46: 9443-9452, 2007

82. Tsuchida M, Emi Y, Kida Y and Sakaguchi M: Human ABC transporter isoform B6 (ABCB6) localizes primarily in the Golgi apparatus. Biochem Biophys Res Commun 369: 369-375, 2008.

83. Matsumoto K, Hagiya Y, Endo Y, Nakajima M, Ishizuka M, Tanaka T and Ogura S: Effects of plasma membrane ABCB6 on 5-aminolevulinic acid (ALA)-induced porphyrin accumulation in vitro: Tumor cell response to hypoxia. Photodiagnosis Photodyn Ther 12: 45-51, 2015.

84. Robey RW,Steadman K,PolgarO and Bates SE: ABCG2-mediated transport of photosensitizers: Potential impact on photodynamic therapy. Cancer Biol Ther 4: 187-194, 2005.

85. Barron GA, Moseley H and Woods JA: Differential sensitivity in cell lines to photodynamic therapy in combination with ABCG2 inhibition. J Photochem Photobiol B 126: 87-96, 2013.

86. Ogawa M, Kosaka N, Choyke PL and Kobayashi H: H-type dimer formation of fluorophores: A mechanism for activatable, in vivo optical molecular imaging. ACS Chem Biol 4: 535-546, 2009.

87. Tansi F, Kallweit E, Kaether C, Kappe K, Schumann C, Hilger I and Reissmann S: Internalization of near-infrared fluorescently labeled activatable cell-penetrating peptide and of proteins into human fibrosarcoma cell line HT-1080. J Cell Biochem 116, 1222-1231, 2015

88. Rizzo LY, Theek B, Storm G, Kiessling F and Lammers T: Recent progress in nanomedicine: Therapeutic, diagnostic and theranostic applications. Curr Opin Biotechnol 24: 1159-1166, 2013. 
89. Tansi FL, Rüger R, Rabenhold M, Steiniger F, Fahr A, Kaiser WA and Hilger I: Liposomal encapsulation of a near-infrared fluorophore enhances fluorescence quenching and reliable whole body optical imaging upon activation in vivo. Small 9: 3659-3669, 2013.

90. Rüger R, Tansi FL, Rabenhold M, Steiniger F, Kontermann RE, Fahr A and Hilger I: In vivo near-infrared fluorescence imaging of FAP-expressing tumors with activatable FAP-targeted, single-chain Fv-immunoliposomes. J Control Release 186: 1-10, 2014.

91. Kalluri R and Zeisberg M: Fibroblasts in cancer. Nat Rev Cancer 6: 392-401, 2006.

92. Huang Y, Simms AE, Mazur A, Wang S, León NR, Jones B, Aziz $\mathrm{N}$ and Kelly T: Fibroblast activation protein-alpha promotes tumor growth and invasion of breast cancer cells through non-enzymatic functions. Clin Exp Metastasis 28: $567-579,2011$

93. Lee HO, Mullins SR, Franco-Barraza J, Valianou M, Cukierman E and Cheng JD: FAP-overexpressing fibroblasts produce an extracellular matrix that enhances invasive velocity and directionality of pancreatic cancer cells. BMC Cancer 11: 245,2011

94.Zhi K, Shen X, Zhang H and Bi J: Cancer-associated fibroblasts are positively correlated with metastatic potential of human gastric cancers. J Exp Clin Cancer Res 29: 66, 2010.

95. Tommelein J, Verset L, Boterberg T, Demetter P, Bracke M and De Wever O: Cancer-associated fibroblasts connect metastasis-promoting communication in colorectal cancer. Front Oncol 5: 63, 2015.

96. Garin-Chesa P, Old LJ and Rettig WJ: Cell surface glycoprotein of reactive stromal fibroblasts as a potential antibody target in human epithelial cancers. Proc Natl Acad Sci USA 87: 7235-7239, 1990.

97. Albert MB, Steinberg WM and Henry JP: Elevated serum levels of tumor marker CA19-9 in acute cholangitis. Dig Dis Sci 33. $1223-1225,1988$.

98. Benamouzig R, Buffet C, Fourre C, Ink O, Moati F and Etienne JP: Serum levels of carbohydrate antigenic determinant (CA 19.9) in obstructive jaundice. Dig Dis Sci 34: 1640-1642, 1989.

99. Encabo G and Ruibal A: Seric CA 19.9 levels in patients with non tumoral pathologies. Our experience in 892 cases. Bull Cancer 73: 256-259, 1986.

100. Gupta MK, Arciaga R, Bocci L, Tubbs R, Bukowski R and Deodhar SD: Measurement of a monoclonal-antibody-defined antigen (CA19-9) in the sera of patients with malignant and nonmalignant diseases. Comparison with carcinoembryonic antigen. Cancer 56: 277-283, 1985.

101. Haglund C, Roberts PJ, Jalanko H and Kuusela P: Tumour markers CA 19-9 and CA 50 in digestive tract malignancies. Scand J Gastroenterol 27: 169-174, 1992.

102. Loy TS, Sharp SC, Andershock CJ and Craig SB: Distribution of CA 19-9 in adenocarcinomas and transitional cell carcinomas. An immunohistochemical study of 527 cases. Am J Clin Pathol 99: 726-728, 1993.

103. Makovitzky J: The distribution and localization of the monoclonal antibody-defined antigen 19-9 (CA19-9) in chronic pancreatitis and pancreatic carcinoma. An immunohistochemical study. Virchows Arch B Cell Pathol Incl Mol Pathol 51: 535-544, 1986.

104. Magnani JL, Steplewski Z, Koprowski H and Ginsburg V: Identification of the gastrointestinal and pancreatic cancer-associated antigen detected by monoclonal antibody 19-9 in the sera of patients as a mucin. Cancer Res 43: 5489-5492, 1983.
105. Girgis MD, Kenanova V, Olafsen T, McCabe KE, Wu AM and Tomlinson JS: Anti-CA19-9 diabody as a PET imaging probe for pancreas cancer. J Surg Res 170: 169-178, 2011.

106. Sawada R, Sun SM, Wu X, Hong F, Ragupathi G, Livingston PO and Scholz WW: Human monoclonal antibodies to sialyl-Lewis (CA19.9) with potent CDC, ADCC, and antitumor activity. Clin Cancer Res 17: 1024-1032, 2011.

107. Houghton JL, Zeglis BM, Abdel-Atti D, Aggeler R, Sawada R, Agnew BJ, Scholz WW and Lewis JS: Site-specifically labeled CA19.9-targeted immunoconjugates for the PET, NIRF, and multimodal PET/NIRF imaging of pancreatic cancer. Proc Natl Acad Sci USA 112: 15850-15855, 2015.

108. Li CH, Kuo TR, Su HJ, Lai WY, Yang PC, Chen JS, Wang DY, $\mathrm{Wu}$ YC and Chen CC: Fluorescence-guided probes of aptamer-targeted gold nanoparticles with computed tomography imaging accesses for in vivo tumor resection. Sci Rep 5: 15675, 2015.

109. Góra J and Latajka R: Involvement of cysteine proteases in cancer. Curr Med Chem 22: 944-957, 2015.

110. Ofori LO, Withana NP, Prestwood TR, Verdoes M, Brady JJ, Winslow MM, Sorger J and Bogyo M: Design of protease activated optical contrast agents that exploit a latent lysosomotropic effect for use in fluorescence-guided surgery. ACS Chem Biol 10: 1977-1988, 2015

111. Kelemen LE: The role of folate receptor alpha in cancer development, progression and treatment: Cause, consequence or innocent bystander? Int J Cancer 119: 243-250, 2006.

112. Low PS and Antony AC: Folate receptor-targeted drugs for cancer and inflammatory diseases. Adv Drug Deliv Rev 56: 1055-1058, 2004.

113. Low PS, Henne WA and Doorneweerd DD: Discovery and development of folic-acid-based receptor targeting for imaging and therapy of cancer and inflammatory diseases. Acc Chem Res 41: 120-129, 2008

114. Low PS and Kularatne SA: Folate-targeted therapeutic and imaging agents for cancer. Curr Opin Chem Biol 13: 256-262, 2009 .

115. Lu Y, Sega E and Low PS: Folate receptor-targeted immunotherapy: Induction of humoral and cellular immunity against hapten-decorated cancer cells. Int J Cancer 116: 710-719, 2005.

116. Lu Y, Xu LC, Parker N, Westrick E, Reddy JA, Vetzel M, Low PS and Leamon CP: Preclinical pharmacokinetics, tissue distribution, and antitumor activity of a folate-hapten conjugate-targeted immunotherapy in hapten-immunized mice. Mol Cancer Ther 5: 3258-3267, 2006.

117. O'Shannessy DJ, Yu G, Smale R, Fu YS, Singhal S, Thiel RP, Somers EB and Vachani A: Folate receptor alpha expression in lung cancer: Diagnostic and prognostic significance. Oncotarget 3: 414-425, 2012.

118. De Jesus E, Keating JJ, Kularatne SA, Jiang J, Judy R, Predina J, Nie S, Low P and Singhal S: Comparison of folate receptor targeted optical contrast agents for intraoperative molecular imaging. Int J Mol Imaging 2015: 469047, 2015.

119. Srinivasarao M, Galliford CV and Low PS: Principles in the design of ligand-targeted cancer therapeutics and imaging agents. Nat Rev Drug Discov 14: 203-219, 2015.

This work is licensed under a Creative Commons Attribution-NonCommercial-NoDerivatives 4.0 International (CC BY-NC-ND 4.0) License. 